\begin{tabular}{|c|c|}
\hline \multirow{3}{*}{ 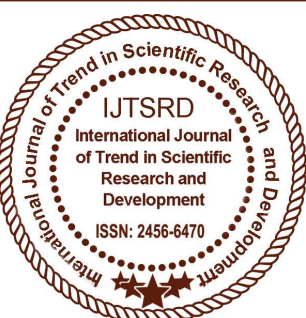 } & $\begin{array}{l}\text { International Journal of Trend in Scientific } \\
\text { Research and Development (IJTSRD) }\end{array}$ \\
\hline & Open Access Journal \\
\hline & ISSN No: 2456 - 6470 | www.ijtsrd.com | Volume - 2 | Issue -3 \\
\hline
\end{tabular}

\title{
Mathematical Differential Solution of Flow \& Head-loss in the Flow- correction \& Design of Distribution Network of Water Supply
}

\author{
Prasanta Biswas \\ Assistant Professor, Civil Engineering Department, Global Institute of Technology \& Management \\ (affiliated \& approved by the West Bengal University of Technology), \\ NH-34 Bhatjangla Nadia, West Bengal, India
}

\section{ABSTRACT}

This study has explained a method of solution of general flow problem by mathematics. The flowproblem is the Darcy-Weisbach formula of the headloss, i.e., $\mathrm{H}_{\mathrm{L}}=\mathrm{KQ}^{\mathrm{x}}$. This equation has been transformed into the Leibnitz's form of the differential equation \& then solved subsequently, considering suitable functionary variables for the derivation as applicable. This way of solution takes the feature of inner variables of a problem to limelight which might not achieve the breakthrough instead by any other way of the available solution in mathematics. Ultimately, in this study, the flowcorrection has got to be a different dimension by the mode of application of mathematics. With the final form of the differential solution, the head-loss estimation has been adjusted for the loops in a distribution network in order to get the given flows passing through the pipe-loops made into the subsequent corrected values. Future scope of this study is enormous; the following up of this study's initiative proceeding for the numerous subjective fields of concern \& lastly not the least indeed, the further research on the outcomes determined in this study by such application of the mathematical passage to go to finding out its further implication.

Keywords: Head-loss, Pipe-flow, Darcy-Weisbach Equation, Leibnitz's differential form, Flowcorrection, Distribution network, Water supply.

\section{Introduction}

Existence is a struggle. It is severe while the existence becomes a 'ruling' existence. It is of any magnitude is highly required in every field. Although there is the certain thing which even with having the existence but it's due to some mere effects of living become of nonexistence. This transformation from one state to another may occur at any time in this world. It may be for the world's choice/wish upon the existence. But how a particular existence tries/attempts to make safety all around is the degree of its sustainability. And, this is continuous \& has been since world's existence came into the universe. Intrepretation goodly is the work of good people; but the Nature probably does not want the world remain only with such. Like good/bad, there is this type of differentiating sub-forms in everything's existence. More interestingly, as its inheritence deinition it's hard to tell about future of any existence - the world is rapidly changing always; there is no minute space available for the world to rest on. And, consequently no one can confirm the 'existence' in future days, even after a minute elapses also. The world perhaps believes its continuous working as worship to universe.

A philosophy is always applied while a fundamental is prepared. The extraction/equation formed by the philosophy right from the inception starts to be under struggling or invalidity over its existence. Modification is the formative word of this struggle -it may be for the time-bounded need merely. Complete extinction is not quite expected although on any philophical work. In the world each \& every theory/fundamental has been experiencing such levels of struggles of existence. One of such has been 
explained here in this study. It's related about application of a mathematical concept (Leibnitz's differential form) with the purview of the design of water supply network system. The differential equation form which is $\mathbf{d y} / \mathbf{d x}+\mathbf{p y}=\mathbf{D}$ has been prepared from the general equation of the pipe-loop head-loss $\mathrm{H}_{\mathrm{L}}=\mathrm{KQ}^{\mathrm{x}}$ of the Darcy-Weisbach(D-W) fundamental. The Leibnitz form of the D-W's equation has shown a new form of the formation \& given the idea/realization about the embodiment it has got. It's nonetheless the flow-correction to be estimated using the new form of the equation of $\mathrm{D}-\mathrm{W}$ shall open up new research doors in the design of the distribution network. In this regard, the term 'loop' is used to indicate the small network of number of pipes , say 3 or 4, maintaining a flow mechanism all around them.

Moreover the forms of the expressions coming out during the preparation of the transformed form of such does give the rendering effects of evolving nature that is rather of much interesting field of knowledge also.

\section{GOALS OF THE STUDY}

i. To examine the Head-loss $\left(\mathrm{H}_{\mathrm{L}}\right)$ applying the Leibnitz's differential equation.

ii. To determine the degree of easeness of the process of entire estimation while the $\mathrm{H}_{\mathrm{L}}$ under such application mathematically.

iii. To find out the changes happening in the interrelated variables during the differential solution \& production of any possible variables of different but useful kind that might be existing/have come out from such transformation to knoe them better for the useful apply.

\section{ASSUMPTION}

i. The applied Leibnitz form of the differential equation is equally valid by its own entirety, as it's formed by the famous scientist Leibnitz.

ii. Like (i), the $\mathrm{H}_{\mathrm{L}}=\mathrm{KQ}^{\mathrm{x}}$ is also applied \& its formative variables are as same as it's applied to become of such.

iii. The boundary condition is suitably applied with respect to the equation $\mathrm{H}_{\mathrm{L}}=\mathrm{KQ}^{\mathrm{x}}$ to find out the integration constant. iv. The transformation is coherently applied of the differential form of the equation $\mathrm{H}_{\mathrm{L}}=\mathrm{KQ}^{\mathrm{x}}$ by the Leibnitz's differential formation.

$v$. $K$, $x$ remain same as it's in the equation $H_{L}=K_{Q}{ }^{x}$ \& stay unchanged in the differential transformation also.

vi. Continuity of flow in pipe is assumed.

\section{METHODOLOGY}

Behind a particular expression, there are in general various 'defining' factors involved. Some of these may have lesser importance \& some may not or rather, be of very high altitude instead. Also, overall application \& demand of the expression, as a whole, depends on the precision of its built-up \& on the outcomes it generates. Limitation of each such equation always gives the force of uncertainty. And, in order to eradicate this problem, many a times it is squeezed into some shortened form; but in that, approximation comes into picture of its outcomes.

In this paper, the general differential form of Leibnitz equation \& its solution has been used \& applied In doing so, the general equation $\mathrm{H}_{\mathrm{L}}=\mathrm{KQ}^{\mathrm{x}}$ has been made up of so \& solved by the conventional way the Leibnitz form of equation requires to get solved through, mathematically. The final form of the equation, so derived, has shown its all which is of self-expressive kind. This technique of formulation may also be similarly applied to expression $\mathrm{Q}=\left(\mathrm{H}_{\mathrm{L}} / \mathrm{K}\right)^{(1 / \mathrm{x})}$, in which case the derivation follows along the path of unknown $\mathrm{Q}$ for given $\mathrm{H}_{\mathrm{L}}$ 's. But, the both ways of methodology determine their own variables of determination in the usual way of Leibnitz's formulation technique. By the way, the final form of equation, be it for $\mathrm{H}_{\mathrm{L}}$ or $\mathrm{Q}$, shall be required to get corrected by any suitable mode of formulation, say Hardy-Cross Method.

The detail derivation, description \& its required essential factorial attachments forming the methodology of this paper is given as follows -

The common general form of the $\mathrm{D}-\mathrm{W}$ is given by

$$
H_{L}=K Q^{x}
$$

Derivating it with resect to $\mathrm{Q}$,

$$
\frac{d H_{L}}{d Q}=\frac{d}{d Q}\left(K Q^{x}\right)=K \frac{d Q^{x}}{d Q}+Q^{x} \frac{d K}{d Q}
$$




$$
\begin{gathered}
\frac{d H_{L}}{d Q}=K(x) Q^{x-1}+Q^{x} \frac{d K}{d Q}=(x) \frac{K Q^{x}}{Q}+Q^{x} \frac{d K}{d Q} \\
\frac{d H_{L}}{d Q}=(x) \frac{H_{L}}{Q}+\left(Q^{x}\right) \frac{d K}{d Q}
\end{gathered}
$$

Assume $r=Q, Y=H_{L}$; where $H_{L}$ is evident to be a function of the discharge.

$\frac{d Y}{d r}+\left(\frac{-x}{r}\right)=\left(r^{x}\right)\left(\frac{d K}{d r}\right)$

... Eq.(1)

Eq.(1) is similar to the Leibnitz's form of the differential equation which is given by

$\left(\frac{d Y}{d X}\right)+P Y=D$; where, $\mathrm{P} \& \mathrm{D}$ be the differential coefficients $\&$ is the function of $Y \& r$.

Relating Eq.(1) with the above Leibnitz's form of the differential equation

$P=\left(\frac{-x}{r}\right) \& D=\left(r^{x}\right)\left(\frac{d K}{d r}\right)$

Solution to this equation, Eq.(1), is determined using the impacting factor as,

$Y(I . F)=\int D(I . F)+c$

...Eq.(2)

where the I.F $=$ Impact factor $e^{\int P d r}=e^{\int\left(\frac{-x}{r}\right) d r}$

$\mathrm{c}=$ integration constant (to be found from boundary condition).

$Y e^{\int P d r}=\int D e^{\int P d r}+c$

...Eq.(3)

Eq.(3) is the differential soultion given by the Leibnitz's solution of the common differential form as discussed. The solution of the differential head-loss equation as determined in the Eq.(3) is now derived as follows -

First of all the Left-hand part of the Eq.(3) is determined as

$$
\begin{gathered}
Y e^{\int P d r}=Y e^{\int\left(\frac{-x}{r}\right) d r}=(Y) e^{\left(\frac{x}{r^{2}}\right)}=(Y) e^{\left(\frac{x}{Q^{2}}\right)} \\
=\left(H_{L}\right) e^{\left(\frac{x}{Q^{2}}\right)}
\end{gathered}
$$

Now the Right-hand part of the Eq.(3) is determined,

$$
\begin{aligned}
\int D e^{\int P d r}=\int & {\left[\left(r^{x}\right) \frac{d K}{d r}\right] e^{\left(\frac{x}{r^{2}}\right)} d r } \\
& =\int\left[\left(Q^{x}\right) \frac{d K}{d Q}\right] e^{\left(\frac{x}{Q^{2}}\right)} d Q \\
& =\frac{d K}{d Q} \int\left[\left(Q^{x}\right)\right] e^{\left(\frac{x}{Q^{2}}\right)} d Q
\end{aligned}
$$

$$
\begin{array}{r}
\int D e^{\int P d r}=\left(\frac{d K}{d Q}\right) \int\left[\left(Q^{x}\right)\right] e^{\left(\frac{x}{Q^{2}}\right)} d Q \\
=\left[\left(\frac{d K}{d Q}\right)\right]\left[\left(Q^{x}\right) e^{\left(\frac{x}{Q^{2}}\right)}\left(\frac{1}{x}\right)\left(\frac{-1}{Q}\right)+e^{\left(\frac{x}{Q^{2}}\right)} \frac{Q^{x+1}}{x+1}\right]
\end{array}
$$$$
=\left(\frac{d K}{d Q}\right)\left[\frac{Q^{x+1}}{x+1} e^{\left(\frac{x}{Q^{2}}\right)}-\frac{Q^{x-1}}{x} e^{\left(\frac{x}{Q^{2}}\right)}\right]
$$

$=\left(\frac{d K}{d Q}\right) e^{\left(\frac{x}{Q^{2}}\right)}\left[\frac{Q^{x+1}}{x+1}-\frac{Q^{x-1}}{x}\right]$

The Eq.(3) is now determined as

$$
\left(H_{L}\right) e^{\left(\frac{x}{Q^{2}}\right)}=\left[\frac{Q^{x+1}}{x+1}-\frac{Q^{x-1}}{x}\right]\left(\frac{d K}{d Q}\right) e^{\left(\frac{x}{Q^{2}}\right)}+c
$$

$$
\left(H_{L}\right)=\left[\frac{Q^{x+1}}{x+1}-\left(\frac{Q^{x-1}}{x}\right)\right]\left(\frac{d K}{d Q}\right)+c\left\{e^{-\left(\frac{x}{Q^{2}}\right)}\right\}
$$

$\left(H_{L}\right)=\left[\frac{Q^{x+1}}{x+1}-\left(\frac{Q^{x-1}}{x}\right)\right]\left(\frac{d K}{d Q}\right)+c 1$

..Eq.(4)

where, $c 1=c\left\{e^{-\left(\frac{x}{Q^{2}}\right)}\right\}$ Integration coefficient. Like ' $c$ ', $\mathrm{cl}$ is to be found from its boundary condition.

From the Hazen-William equation, the value of $\mathrm{K}$ is found as,

$\mathrm{K}=$ function of $\left(\mathrm{L} / \mathrm{d}^{4.87}\right)=(1 / 470) \quad\left(\mathrm{L} / \mathrm{d}^{4.87}\right)$ ..Eq.(5)

where, $L=$ Pipe length $\& d=$ Pipe dia. The ratio of $(\mathrm{dK} / \mathrm{dQ})$ should be derived \& found from the functionary relation of $\mathrm{K}$ with $\mathrm{L} \& \mathrm{~d}$ as given in the Eq.(5). Continuity of flow in pipe network may be considered in this derivation of $(\mathrm{dK} / \mathrm{dQ})$.

From the Eq.(4) of the head-loss the necessary correction and/or the estimation of the flow-variable could be determined in the design of distribution network (Table 1). Its procedure is given step-wise in the following - 


\section{Procedure of the Design:}

\section{Method I (for Individual pipe)}

i. Assume $Q$ value as $Q_{a}$ for the pipe flow.

ii. Also assume the value of $\mathrm{K} \& \mathrm{x}$.

iii. The value of the derivation of $\mathrm{dK} / \mathrm{dQ}$ should be chosen on assumed $\mathrm{d} \& \mathrm{~L}$ (or flow area).

iv. The constant c \& $\mathrm{c} 1$ should be determined from its connected boundary condition.

v. Estimate the $\mathrm{H}_{\mathrm{L}}$ value as given in Eq.(4), as to be desired of - it may be zero or else.

vi. The steps from (i) to (v) is for individual pipe's attainment towards the value of head-loss $\left(\mathrm{H}_{\mathrm{L}}\right)$ in a loop of pipe(Table 1).

\section{Method II (for Pipe Loop)}

i. For a loop of pipes, the sets of values given in the columns of the Table 1 are to be determined by the number of pipes available for the loop. Thereby if there are three pipes in a loop then there shall be the one set (of three Sl's. In col.1, Table 1) comprising of the values (Table 1) for the exemplary three pipes. ii. Sum all the $\mathrm{H}_{\mathrm{L}} \mathrm{S}$ of the pipes in the loop(for three pipes, $\mathrm{H}_{\mathrm{L}}=\mathrm{H}_{\mathrm{L}} 1+\mathrm{H}_{\mathrm{L}} 2+\mathrm{H}_{\mathrm{L}} 3$ ).

iii. Bring the $\mathrm{H}_{\mathrm{L}}$ value to the design or desired one \& furnish the backward estimation \& find the corrected flows for the pipes. But the distribution of flows or the $\mathrm{H}_{\mathrm{L}} \mathrm{s}$ should be reasonable.

iv. There may also be some of the choiceful iteration done in choosing the correct flows/the $\mathrm{H}_{\mathrm{L}} \mathrm{s}$ in order to have its correct ones.

The procedure of the Method I is termed as 'Foreward' estimation \& for the Method II as 'Backward' estimation. And, the design equation about the Table 1 for both the cases of individual pipe $\&$ pipe-loop is given by the assumed flow as

Table1. Distribution Network Design ${ }^{\#}$ (for individual pipe of a pipe-loop)

\begin{tabular}{|c|c|c|c|c|c|c|c|}
\hline SI. & $\begin{array}{l}Q=Q_{a}= \\
\text { assumed } \\
\text { flow }\end{array}$ & $\mathrm{K}$ & $\bar{x}$ & $\overline{d K / d Q_{a}}$ & c1 & $\overline{\mathrm{H}_{\mathrm{L}}}$ & Remarks \\
\hline col.(1) & col.(2) & col.(3) & col.(4) & col.(5) & col.(6) & col.(7) & col.(8) \\
\hline 1 & \multicolumn{6}{|c|}{$\begin{array}{c}\text { Estimation is done in this stage on the basis of the given } \\
\text { (raw) data. } \\
\text { FOREWARD }\end{array}$} & $\mathrm{Qa}=$ assumed flow \\
\hline 2 & \multicolumn{6}{|c|}{$\begin{array}{l}\text { At this stage estimation is to be done backward } \\
\text { (considering a suitable value to } \mathrm{H}_{\mathrm{L}} \text { ). }\end{array}$} & $\begin{array}{l}\text { It's preferred of } \mathrm{H}_{\mathrm{L}} \text { as } \\
\text { zero but for } \\
\text { experience it the } \mathrm{H}_{\mathrm{L}} \\
\text { value may be taken } \\
\text { one except the zero } \\
\text { value. }\end{array}$ \\
\hline 3 & \multicolumn{6}{|c|}{$\begin{array}{l}\text { While experiencing the estimation should proceed to this } \\
\text { level \& beyond till attainment of the satisfactory value. }\end{array}$} & $\begin{array}{l}\text { This direction may be } \\
\text { forward or backward. }\end{array}$ \\
\hline
\end{tabular}

\#precision depends on the number of iteration as well as the designer's experience.

The Table1 is completely deterministic to the value desired. In this case of the network design, sign

$$
\left(H_{L}\right)=\left[\frac{Q_{a}^{x+1}}{x+1}-\left(\frac{Q_{a}^{x-1}}{x}\right)\right]\left(\frac{d K}{d Q_{a}}\right)+c 1
$$




\section{CONCLUSION \& FUTURE SCOPE}

i. This study's research scopes are numerous.

a. Firstly, it opens up the way of formulation of different variety towards finding the more general form of $\mathrm{H}_{\mathrm{L}}$ or $\mathrm{Q}$.

b. Secondly, it is presumed here in this study that the better precision level shall be able to be required, although the estimation may be seemed as complex one.

c. Thirdly, the formulation as derived using the famous Leibnitz's general differential form gives the both ways of methodology - the differential components have given the clearer picture inside the mechanism of pipe-flow.

ii. As said in the goals of this study, several modes of mathematical form of the various equation may be used for making the equation $\mathrm{H}_{\mathrm{L}}=\mathrm{KQ}^{\mathrm{x}}$ synchronous to them \& finding out the corresponding solution may be its further research $\&$ the needful finding to the zones still residing in darkness.

iii. Much research may be necessary on the value/functional variables of $\mathrm{K}$ (i.e $\mathrm{dK} / \mathrm{dQ}$ ) so far as the final equation of $\mathrm{H}_{\mathrm{L}}$ is defined of.

\section{REFERENCE}

1) [1] Wikipedia, the free encyclopedia, DarcyWeisbach equation https://en.wikipedia.org/wiki/Darcy\%E2\%80\%93 Weisbach_equation

2) Wikipedia, the free encyclopedia, HazenWilliams equation https://en.wikipedia.org/wiki/Hazen $\%$ E2\%80\%93 Williams_equation

3) Wikipedia, the free encyclopedia, Integrating factor https://en.wikipedia.org/wiki/Integrating_factor 